\title{
Tecnologias digitais móveis: reterritorialização dos cotidianos escolares
}

\section{Mobile digital technologies: reterritorialization of school everyday life}

\author{
Salete de Fátima Noro Cordeiro ${ }^{1}$ \\ Maria Helena Silveira Bonilla ${ }^{1}$
}

\begin{abstract}
RESUMO
As tecnologias digitais móveis têm engendrado práticas reterritorializantes, a partir das quais os interagentes/praticantes têm criado espaços/tempos outros para ser, estar, criar e viver. O cotidiano escolar também vem sendo marcado intensamente pelas táticas de seus interagentes/praticantes que criam territorialidades outras a partir dessas tecnologias. Em vista disso, buscamos refletir sobre os movimentos ocorridos nos cotidianos escolares a partir da chegada das tecnologias digitais móveis em três escolas públicas do ensino fundamental. Para tanto, desenvolvemos uma cartografia dos processos que envolvem o fenômeno, descrevendo e buscando encontrar/ identificar suas intensidades. Como resultados da pesquisa, apontamos a criação de territórios onde o digital passa a ser estruturante de práticas de produção de conteúdos, conhecimentos e significados e de reorganização do espaço escolar.
\end{abstract}

Palavras-chave: tecnologias digitais móveis; territorialidades; cotidiano escolar.

\begin{abstract}
Mobile digital technologies have generated reterritorializing practices, from which the interacting/practitioners have created other spaces/times to be, create and live. The school everyday life has also been marked intensely by tactics of these interacting/practitioners who create other territorialities
\end{abstract}

DOI: $10.1590 / 0104-4060.39998$

1 Universidade Federal da Bahia. Faculdade de Educação. Salvador, Bahia, Brasil. Av. Reitor Miguel Calmon, s/n. CEP: 40110-100. 
from these technologies. In view of this, we reflect on the movements in school everyday life since the arrival of mobile digital technologies in three public elementary schools. To this end, we developed a mapping of processes involving the phenomenon, describing and seeking to find/identify their strengths. The results of the research pointed out the creation of territories where digital tools are now structuring practices of content production, knowledge and meanings and reorganizing the school space.

Keywords: mobile digital technologies; territorialities; school everyday life.

\section{Introdução}

A presença das tecnologias digitais móveis tem engendrado práticas sociais que envolvem o surgimento de posturas outras dos interagentes/praticantes ${ }^{2}$ em relação aos conteúdos que recebem e emitem. Acessar, reconstruir, emitir informações e conteúdos ganham dinâmicas diferenciadas no cotidiano das pessoas comuns com o advento das tecnologias da informação e comunicação, mais intensamente a partir da web 2.0. O que tem surpreendido, comparando-se às experiências precedentes, é a facilidade, a velocidade e as maneiras como as relações entre interagentes, conteúdos, meios digitais, espaços físico e eletrônico têm se manifestado. A mobilidade digital, presente no cotidiano de milhares de pessoas, permite tanto o acesso instantâneo à comunicação, como a possibilidade imediata de responder, opinar, reagir às mensagens e informações recebidas ou acessadas, independentemente da localização dos interagentes.

Martin-Barbero (2004) defende que a presença das tecnologias disponíveis, atualmente, colabora para que o direito à comunicação, um direito de todos, não fique restrito ao monopólio, nem da indústria, nem dos especialistas em comunicação. Todos podem ser receptores, produtores e emissores de conteúdos. Especialmente, os jovens integram-se a esse movimento, utilizando intensamente seus aparelhos de telefone celular, seus smartphones para comunicar. Os usos são diversos e neles estão presentes ressignificações, re-desterritorializações e subjetivações. Muitas vezes, torna-se difícil compreendê-los na voragem comu-

2 Utilizamos a expressão interagentes/praticantes por trabalharmos com os referenciais da teoria dos cotidianos e da cultura digital. O termo interagente é de autoria de Alex Primo (2008), utilizado em substituição ao de internauta, ou usuário, por ser mais abrangente e não reportar somente à atividade de consumo de informações em rede. Já o termo praticante é oriundo da teoria dos cotidianos (ALVES, 1998; CERTEAU, 2008; CERTEAU; GIRARD; MAYOL, 2008), e refere-se aos sujeitos ordinários, aqueles que, diariamente, vivenciam e praticam seu cotidiano. 
nicacional, mas é visível a facilidade com que as novas gerações têm incorporado os artefatos, e também criado cultura, a partir das brechas que se apresentam em sua realidade arbitrária, coercitiva, reprodutiva e linear, desencadeando processos de interação, intervenção e criação de outros territórios simbólicos.

Buscamos, em pesquisa realizada durante o curso de Doutorado em Educação, compreender como os praticantes dos cotidianos de três escolas públicas das redes municipais de Salvador-BA e Aracaju-SE, onde está presente o Projeto Um computador Por Aluno - $\mathrm{UCA}^{3}$, e onde também está presente uma grande quantidade de dispositivos móveis (celulares e smartphones), reelaboravam seus conceitos e práticas a partir do uso dessas tecnologias. Para dar conta da complexidade que envolvia o fenômeno, buscamos aporte teórico metodológico na teoria dos cotidianos (CERTEAU, 2008; CERTEAU; GIRARD; MAYOL, 2008; HELLER, 2008; LEFEBVRE, 1991) e da cultura digital. (LEMOS, 2007, 2008a; LEMOS; LÉVY, 2010; LÉVY, 1998, 1999; SANTAELLA, 2007). Lançamos mão da cartografia, de Deleuze e Guattari (2012), para construir um mapeamento dos processos desencadeados nas escolas, descrevendo e identificando/apontando suas intensidades. Realizamos rodas de conversas, das quais participaram alunos, professores, funcionários e gestores das escolas, para conhecer, acompanhar e analisar a tessitura das suas narrativas ${ }^{4}$. Ainda utilizamos o referencial teórico do método indiciário de Ginzburg (1989), analisando vídeos e fotografias produzidos por nós e pelos próprios praticantes.

Escolhemos a escola como locus de investigação porque atende principalmente a população jovem e é dentro dela que eles trocam torpedos com colegas da mesma sala de aula, da sala vizinha ou mesmo com amigos de outros lugares; jogam, acessam redes sociais, tiram fotos e filmam, publicam em seus blogs e microblogs. Em nossa compreensão, esses são momentos, instantes (BACHELARD, 2007), preciosos que libertam os praticantes, seus corpos e suas mentes da aula enfadonha, do professor chato, do conteúdo desinteressante, do ambiente pobre em estética, e criam linhas de fuga, provocam desterritorializações e reterritorializações, onde o pensamento voa e o corpo não carrega mais o fardo de estar na escola que não acompanhou o ritmo do seu tempo. (GREEN; BIGUM, 2009). Os jovens buscam no entretenimento, em práticas evasivas ou não, na interação ou comunicação, fazer com que aquele tempo seja suprimido, passe despercebido ou o mais rapidamente possível. A

3 Disponível em: <http:/www.fnde.gov.br/programas/programa-nacional-de-tecnologia-educacional-proinfo/proinfo-projeto-um-computador-por-aluno-uca>. Acesso em: 18 jun. 2015.

4 As falas são identificadas conforme as escolas (A, B, C), categorias (professor, P; aluno, $\mathrm{A}$; coordenador, $\mathrm{C}$; funcionário, $\mathrm{F}$; seguido de um número) e conforme a roda de conversa que participou (R1, R2, R3...). 
imersão nesses cotidianos possibilitou perceber as táticas desenvolvidas pelos praticantes/interagentes que reterritorializam os espaços/tempos ${ }^{5}$ escolares, conforme analisaremos neste texto.

\section{Mobilidade e processos desterritorializantes}

O conceito de mobilidade ganha novo significado a partir da revolução digital, da miniaturização de aparelhos e de sua conectividade com redes de comunicação, possibilitando misturar/articular o digital com o físico, criando um ambiente de tecnologia semântica e cognitiva, que começa a remodelar as nossas formas de fazer, criar, pensar e relacionar em nossa vida cotidiana, no trabalho, no lar, no lazer, na educação ou em qualquer espaço que possamos habitar. Concordamos com Pellanda (2009), quando diz que há um borramento de fronteiras entre o espaço físico e o virtual. Se antes estávamos restritos ao uso da conexão virtual presa a fios, localizada dentro de quatro paredes, agora o espaço físico não é mais uma limitação. "As conexões físicas entre indivíduos são feitas na mesma dimensão da conexão virtual [...]. O virtual se desloca no espaço físico e cria com ele uma relação de complexa cooperação." (PELLANDA, 2006, p. 91).

Com isso, não se sustentam argumentos que apontam a dimensão física como oposta ou separada da dimensão virtual. Tais dimensões, quando conectadas através da mobilidade, da comunicação e das redes, se fundem, imbricam, complementam, potencializam, gerando um novo espaço conceitual, denominado "espaço híbrido" (SOUZA E SILVA, 2004), ou "espaço intersticial" (SANTAELLA, 2007), que enfatiza não apenas o fluxo de transmissão de informação para dentro e para fora do espaço físico, também as novas formas de computação que são utilizadas e as novas práticas que emergem com os usos desses dispositivos.

Lemos (2009a) sugere três dimensões fundamentais da mobilidade: a do pensamento, a física e a informacional. Essas três dimensões estão inter-relacionadas, exercem influência uma sobre a outra, estão permeadas por relações de poder, não podendo ser compreendidas sob uma perspectiva de neutralidade. Essas características são potencializadas e expandidas à medida

5 Espaço/tempo entendido como o imbricamento das relações espaciais e temporais que se dão a partir da interação com o digital. No mesmo espaço/tempo de uma escola marcada pelos ritmos lineares, emerge, pela presença e utilização de práticas digitais síncronas e assíncronas, espaços/tempos outros. 
que os corpos e objetos estão em rede, em movimento pelo espaço físico e digital. A partir das possibilidades de convergência, miniaturização, portabilidade, conectividade, participação, próprios do digital, ganha destaque a mobilidade física, os deslocamentos, tanto do nosso corpo, como dos objetos, mercadorias ou serviços. Deslocamo-nos pelo espaço, caminhando ou sendo levados por meios de transportes, carregando objetos pessoais, dentre eles os dispositivos que nos possibilitam comunicação e interação, o que cria uma dinâmica potente de nossa relação com o ambiente, as coisas, os acontecimentos e as pessoas.

No momento que estamos em movimento pelo espaço físico, vendo, fotografando, filmando, sentindo e percebendo situações, paisagens e fatos, também estamos conectados, recebendo e emitindo informações e conteúdos de diversas naturezas, dialogando com outras pessoas, dispersas em pontos geográficos distintos. Entra em cena, nesse instante, a mobilidade informacional (sistemas de comunicação), que se caracteriza, principalmente, pelos sistemas informacionais móveis, com base digital, em que o acesso às informações e conteúdos depende da possibilidade de acesso às redes (Wireless, bluetooth, $3 G$, $4 G$ ), onde, além de consumir informações, os interagentes/praticantes podem produzir e disponibilizar conteúdos.

Com a mobilidade física, a mobilidade informacional se potencializa, pois podemos estar no local onde um fato ou acontecimento desenrola-se, fazer postagem de vídeos, imagens e ainda interagir em microblogs ou chats, trocando ideias e informações numa dinâmica que acontece em tempo real. Por exemplo, podemos inteirar-nos das situações de trafegabilidade, através do que outros interagentes informaram, e também emitir dados sobre o tráfego da região onde estamos. Por sua vez, a mobilidade do pensamento, que sempre esteve presente nas nossas práticas cotidianas, agora é dinamizada e ganha o potencial da conexão, das redes e do movimento físico por diversos espaços. A qualquer momento, o pensamento e a reflexão podem ser ativados, através da necessidade de comunicação, de processamento de informações, de tomada de decisão, de produção e organização de conteúdos e das diversas maneiras de sua disponibilização.

Definidas essas três características da mobilidade, uma tendo influência sobre a outra, podemos dizer também que quem não tiver acesso à informação e comunicação está, de certa maneira, condenado a imobilidades (social, cultural, econômica). Portanto, a mobilidade varia com o grupo social e com as relações de poder nas quais o sujeito está inserido. Para Lemos (2009a), esse fato implica a necessidade de a mobilidade ser politizada. 
Parece haver hoje uma correlação e ampliação de poderes já que quanto maior a potência de mobilidade informacional-virtual, maior é a mobilidade física e o acesso a objetos e tecnologias. A mobilidade informacional (acesso rápido, pleno e fácil à informação) é correlata à potência (motility) da mobilidade física. Os que podem se movimentar mais facilmente pelo ciberespaço são também os que têm maior autonomia para o deslocamento físico e vice-versa. (LEMOS, 2009a, p. 29).

O conjunto de práticas vivenciais que a mobilidade nos coloca, a dinamização e potencialização do pensamento, do deslocamento e da troca de informação, mediados pelas tecnologias digitais móveis, proporcionam um desprendimento das amarras de um contexto imediato, das limitações de um espaço/tempo cronológicos, delimitados, e sugerem aos interagentes/praticantes serem produtores de dinâmicas mais fluidas e flexíveis, o que potencializa uma reterritorialização e significação de espaços onde podem ser criados "novos sentidos de lugar", através da produção de ambientes de postagens de textos, imagens, mensagens, onde se distribui informação e se participa, cocriando nesse novo espaço. As mobilidades do pensamento, a física e a informacional, portanto, aumentam as ações sobre o espaço físico. "A mobilidade produz espacialização e os lugares devem ser pensados como eventos em um fluxo de práticas sociais, de processos territorializantes e desterritorializantes." (LEMOS, 2009a, p. 31).

Ao definir território, Lemos (2009b) alerta para o fato deste não estar demarcado por fronteiras contíguas, geográficas, mas, principalmente, definido pela ideia de controle, podendo então essas fronteiras extrapolarem o domínio jurídico e adentrarem no campo do simbólico, do cultural, do político. Dominar um território é controlá-lo, controlar seus processos e seus limites. Portanto, para o autor, o conceito de território está relacionado ao acesso, controle e vigilância. Por um lado temos o acesso e controle (sempre relativos) dos interagentes dentro de seu território informacional, território este delimitado por um acesso restrito a quem possui uma senha, que possibilita adentrar ao espaço via e-mails, blogs, sites, redes sociais; delimitado também pela possibilidade de filtrar algumas informações e liberar outras, através de nossas escolhas, controlando a recepção e a emissão (o que, em parte, não ocorria com as mídias de massa). "O lócus de controle desse fluxo informativo é o território informacional, onde o usuário controla o que entra e sai na sua fronteira informacional." (LEMOS, 2009b, p. 43). Por outro lado, há também o controle exercido por governos e instituições privadas, pois ao entrarmos no espaço digital, ao emitirmos informações, existe um outro tipo de controle na rede, mais relacionado à vigilância sobre o que emitimos e recebemos (por exemplo, a quantidade de downloads, em algumas 
circunstâncias, faz com que nossa velocidade de conexão diminua; conforme nossa navegação ou uso do cartão de crédito, recebemos propagandas específicas).

A desterritorialização é o movimento que ocorre nesse território no sentido de busca de uma reterritorialização. As ressignificações, subjetividades que vão sendo processadas e construídas, são linhas de fuga que vão surgindo. Para Lemos (2009b), não existe desterritorialização sem nova reterritorialização. O processo é inerente ao ser humano, sendo próprio do homem construir seu habitat e, nesse processo, mediado pelo simbólico, territorializa e desterritorializa. "Quando podemos criar um 'território' podemos criar um mundo. As questões de território, territorialização e desterritorialização são essenciais ao homem." (LEMOS, 2008b, p. 03).

As atuais formas de reterritorialização são explicitadas por Lemos (2009b) através de três leis que configuram a cultura contemporânea: em primeiro lugar está a liberação do polo da emissão: não temos mais um usuário, temos um interagente, que não apenas consome, também produz e emite conteúdos. A conexão, que permite a emissão desses conteúdos, é a segunda lei e direciona para o compartilhamento desses conteúdos. O que importa é estar em rede e compartilhar, pois a livre circulação de informação e conteúdos estimula práticas de produção livre e colaborativas. Daí emerge a terceira lei, a inteligência coletiva, em que o saber de cada um é reconhecido e valorizado em sua diversidade, e os atos, processos e decisões são coordenados e avaliados em tempo real, a partir de critérios constantemente reavaliados e contextualizados. (LÉVY, 1998, p. 31). Portanto, nada é fixo, a partir da "emissão livre (liberdade de vozes, opiniões, ideias) e conexão (de pessoas ou grupos) há sempre mudança, movimento, linhas de fuga". (LEMOS, 2009b, p. 41).

No que diz respeito aos cotidianos das escolas, estes são espaços/tempos vividos, permeados por uma multiplicidade de relações e de intensidades nas maneiras de ser, estar, permanecer, fazer e comunicar, agora intensificados e expandidos com a presença das tecnologias digitais móveis que possibilitam a criação de territórios com novos sentidos. A reterritorialização dos espaços/ tempos escolares se intensifica na medida em que o digital começa a fazer parte das práticas cotidianas dos interagentes/praticantes desse contexto, onde a dimensão das redes começa a se tornar cada vez mais presente. Os territórios que vão sendo construídos possibilitam relações mais horizontalizadas e plurais, tornando-se potenciais espaços de criação. Em consequência, os praticantes/ interagentes estão reinventando o cotidiano das escolas e a si mesmos. 


\section{Os processos desterritorializantes/reterritolializantes no cotidiano escolar}

As tecnologias digitais móveis entram nos espaços/tempos e cotidiano escolares trazidas, em grande parte, por sua comunidade: alunos, funcionários e professores. Mesmo em comunidades carentes, são os alunos que fazem a tecnologia digital móvel emergir nesse cotidiano, seja através dos usos diversos que fazem desses dispositivos, seja através da tensão que causam ao inserir no espaço educativo outras maneiras de estar, ser e comunicar.

Todo o movimento do uso das tecnologias é intenso e é observado e sentido no cotidiano das escolas, dentro e fora da sala de aula. Não só os professores, também os funcionários percebem a dinâmica sendo alterada através da busca constante pelo sinal de rede, pelos alunos que usam os dispositivos móveis, pelo movimento que desencadeiam para gravar, com os aparelhos celulares, suas coreografias, na hora do recreio. Se por um lado consomem conteúdos diversos como vídeos, músicas e games, por outro, produzem escrita, enviam mensagens via SMS, a todo instante, tiram fotos, fazem montagens, filmam, enviam pelo WhatsApp e colocam em seus perfis no Facebook. Ao entrar nas redes sociais, fazem comentários, curtem, compartilham, adicionam e deletam perfis; verificam os games do momento, transferem para seus aparelhos e buscam tutoriais sobre eles; entram no perfil da rádio local (FM), pedem música, mandam recados; ouvem músicas que baixaram da rede; enfim, estão utilizando, incontrolavelmente, seus aparelhos, fazendo suas escolhas e construindo sua própria identidade.

Eu gosto do celular da minha madrasta. Eu vou no YouTube, fico sabendo a notícia, fico pesquisando um bocado de coisas. Eu gosto muito do YouTube, assistindo filme [...]. E tenho o Facebook [...] meus amigos mandam jogos pra mim. Eu tenho um bocado de coisas na internet $[\ldots]$ gosto de jogos. (A1 R3 Escola B).

Pra mim, me enjoa. De 15 em 15 minutos mandam mensagens pra mim. (A6 R3 Escola C).

Faço tudo, uso pra tudo [...] mensagem, ligação, Facebook... WhatsApp eu gosto. Instagram. (A9 R4 Escola C).

Esse comportamento, provocado pelas tecnologias digitais móveis, toma conta do cotidiano das escolas e salas de aulas. Os alunos não desligam nunca, 
estão sempre conectados, demonstrando uma relação de intensidade e intimidade com as tecnologias digitais. Esses jovens fazem parte de um contexto em que a comunicação é intensa e a informação nunca foi tão fácil de ser acessada, produzida e compartilhada. Essa geração tem acesso multimídia em um único dispositivo, o que a coloca para além de consumidora, como protagonista, avaliando conteúdos, produtos, empresas, ou produzindo seus próprios conteúdos. (TAPSCOTT, 2010). Conforme as práticas vão sendo desenvolvidas por esses jovens, a partir de sua relação com as tecnologias digitais, vão constituindo-se maneiras de ser e estar no mundo, que carregam consigo uma outra cultura e exigem maneiras outras de educar e ser educados.

Segundo Serres (2013), essa geração que chega à escola é completamente diferente em relação às gerações que a antecederam. Os alunos e alunas têm outra cabeça, maneiras diferentes de pensar, de estar, de ser, de conviver, de relacionar, de interagir e de aprender. Essa geração percebe que o conhecimento está na rede e que basta apenas alguns toques na tela de seus dispositivos móveis para ter acesso aos bancos de dados, sites, blogs e páginas, o que lhes possibilita ter à disposição as informações que necessitam, a qualquer momento, em qualquer lugar, sem necessidade de memorização - está tudo disponível! Se antes a centralidade do processo de aprendizagem estava voltada para o professor, que trazia e compartilhava, de alguma maneira, seus conhecimentos, dentro de um tempo e espaço delimitados pelo calendário escolar, período de aula e sequência didática, agora essa centralidade se dissipou, pois os conhecimentos estão disponíveis também no ambiente digital, ao alcance dos praticantes/interagentes a qualquer tempo e em qualquer espaço.

A tecnologia digital, em sua dimensão de mobilidade, cria espaços/tempos híbridos que colocam na berlinda a organização espaço-temporal da escola. Os alunos e alunas não precisam mais chegar em casa para fazer a tarefa, ou ir até a biblioteca pesquisar em livros ou enciclopédias, eles acessam a partir de seus aparelhos móveis os conteúdos necessários para dar conta das atividades diárias passadas pelos professores. Os aparelhos oferecem conectividade ininterruptamente, assim, ao mesmo tempo em que estão enviando torpedos, entrando nas redes sociais, estão tirando fotos do conteúdo que o professor passou no quadro, ou mesmo gravando a aula.

A gente grava as aulas do professor [X] [risos] porque ele passa, ele explica um assunto [...]. E aí quando a gente chega, vai ter prova. Quando a gente não sabe de nada, aí a gente vai ouvir o vídeo. (A5 R4 Escola C). E também batemos fotos na matéria de História. Em algumas vezes quando o povo tá com preguiça de escrever tira foto. Chega em casa e 
copia. [...] é bastante coisa. Também o tempo é pouco porque ele apaga. (A1 R4 Escola C).

Com a presença das tecnologias digitais móveis, o cotidiano da escola amplia-se e é alterado. As alunas e alunos passam a fotografar e gravar as aulas dos professores, compartilham entre si esses conteúdos, e, ao ouvir as gravações, fazem resumos e trocam entre colegas. Eles dizem que em algumas matérias precisam entender o conteúdo porque o professor não espera uma resposta direta e, sim, que eles deem uma explicação contendo o seu entendimento, então precisam ficar atentos à explicação do professor, pois nem sempre encontram o tema no capítulo do livro. Dessa forma, os recursos da fotografia e da gravação auxiliam a capturar as informações e ter acesso a elas tantas vezes quantas acharem necessário. Assim, o espaço/tempo da escola é expandido, chegando tanto na residência dos meninos e meninas como em qualquer outro espaço onde possam estar com seus fones, ouvindo as gravações ou vendo as fotos dos conteúdos.

A possibilidade de conexão com os professores, através das redes sociais, também amplia as dinâmicas espaços-temporais do cotidiano escolar. Os alunos e alunas citam que poucos professores estão adicionados a seus perfis no Facebook, mas que a partir dessa rede é possível se comunicar com esses professores fora do horário de aula. Alguns professores da escola C, por exemplo, colocam no seu perfil os conteúdos que trabalharam em aula, ou dúvidas em relação ao conteúdo.

De vez em quando a gente falta, eu pego sempre com ele. Aí ele diz: essa página, essa... [...] é, pelo Face. [...] é bom porque a gente tá faltando, aí tá adiantando pra gente. Não precisa chegar na escola, a gente já pega em casa e vai adiantando. (A9 R4 Escola C).

[...] ele explica melhor na sala de aula, mas se colocar no Facebook também é bom. [...] acho bom. Porque às vezes o que ele fala na sala de aula ele manda pro Facebook. [...] e a gente não fica se batendo atrás do site. (A8 R2 Escola C).

Essas práticas que vão surgindo, vão emergindo do cotidiano, a partir das fendas, das brechas deixadas pelas práticas instituídas, entre aqueles praticantes mais inteirados, que pedem para o professor adicioná-los, que entram nas redes e chamam o professor, que perguntam, que buscam estabelecer essa relação fora do espaço formal da escola. São táticas dos praticantes/interagentes que vão es- 
tabelecendo outros territórios de comunicação, trocas mais fluidas, dinâmicas e horizontais, que potencializam as relações e as aprendizagens, reterritorializando e atribuindo outros sentidos e significados à escola.

Agora eu estava falando no assunto sobre a autoestima [...] eu pedi, façam uma pesquisa sobre autoestima. [...] uma menina pegou o celular e me mostrou na hora, e estava batendo! Veio acrescentar à minha aula realmente, entendeu. Na hora eu li, li pra eles. Eles: “ah, já fez, que legal!". $\mathrm{Eu}$ tento fazer essa abertura, sabe?! Porque eu acho que é uma forma também de aprender. (P2 Escola B).

Nesse contexto, os estudantes passam a habitar espaços/tempos híbridos. O físico e o virtual fazem parte de um mesmo contexto, colocando aluno e professor em situação de coautoria e potencializando as aprendizagens. Muitas vezes, também usam os espaços/tempos híbridos como táticas para enfrentar a rotina e a estética da escola, a qual não corresponde às suas expectativas e interesses, como fica exemplificado na fala dos alunos das escolas B e C:

Essa escola é muito feia. É sala feia, é parede feia, é tudo feio... é gente feia. [...] Meu... é todo dia assim. Eu prefiro botar meu fonezinho e ouvir música... eu ligo meu som e vou pra outro lugar [...] fico ouvindo música, aí fica tudo melhor... aí eu relaxo... (A1 R1 Escola B).

Bota o fone e ouve música [...]. Quando o professor passa dever prá gente... fica só ele. A gente sai da sala, é como se saísse da sala. É sair da sala sem correr perigo. (A5 R3 Escola C).

Os alunos não se referem apenas à materialidade das coisas, mas a demandas que não são mais supridas pela escola. Através das redes, esses alunos têm acesso a outras estéticas, a outras linguagens, a outras dinâmicas e ritmos. Eles desterritorializam o espaço/tempo escolar e criam outros territórios onde encontram conforto, onde podem ser ouvidos quando entram em suas redes sociais, ou enviam mensagens via SMS, e seus colegas respondem imediatamente a suas postagens. Ganham visibilidade e popularidade em seus sites de relacionamento, passam de uma página da web a outra, do YouTube para o Twitter, deste para o WhatsApp e depois a rádio web ou a músicas que eles mesmos escolheram e gravaram. A necessidade de comunicação é tão intensa que quando acabam os créditos do seu aparelho, passam a usar os do colega. 
Para Michel Serres (2013), há uma fenda entre o que a escola oferece e o que querem os alunos. Para o autor, as estruturas escolares - prédios, pátios de bibliotecas, laboratórios, os próprios saberes - datam de uma época que os alunos não reconhecem mais, pois eles pensam e compreendem o mundo e suas relações de outra maneira. Daí decorre a emergência de táticas e práticas mais em sintonia com suas necessidades e interesses. Evidentemente, as dinâmicas de des-reterritorialização vão se dando de maneiras e com intensidades diferentes, conforme cada contexto. $\mathrm{Na}$ escola $\mathrm{C}$, por exemplo, a infraestrutura colaborou para que os alunos levassem todos os dias seus equipamentos para a escola, e estimulou, até certo ponto, que os professores realizassem atividades com as tecnologias. Mas o que surpreendeu não foram os projetos desenvolvidos pelos professores, que em decorrência da rotatividade foram sendo substituídos no processo da formação oferecida pelo Projeto $\mathrm{UCA}^{6}$. O que chamou atenção foi o fato de que os alunos que receberam seu laptop, que o levaram para casa, continuaram trazendo-o para a escola, circulando com ele, utilizando-o intensamente. Essa intensidade do uso, pelos alunos, fica evidenciada na fala do funcionário da escola $\mathrm{C}$ :

E quando começou, quando eles receberam o laptop, isso daqui virou um inferno. Tinha alunos que não iam pra casa. Tinha rede, pegava rede, eles ficavam direto. Até aconteceu de chegar final de semana, e vir pra escola pra ficar conectado. (F1 Escola C).

O funcionário sente a mudança que aconteceu no cotidiano da escola: "[...] virou um inferno". Não que tenha sido de todo ruim, mas significa que o cotidiano da escola foi alterado profundamente. Se antes os espaços/tempos das escolas eram marcados pela sirene, que demarcava o período de entrada e saída dos alunos, agora, o que determina a presença deles na escola é a conectividade e o laptop. Os alunos vêm para a escola e querem permanecer nela, principalmente nos horários opostos ao horário de aula, em decorrência da possibilidade de estarem conectados em rede.

6 A formação oferecida aos professores, no âmbito do Projeto UCA, esteve sob a responsabilidade das Universidades e dos Núcleos de Tecnologia Educacional (NTE), e tinha como objetivo proporcionar familiaridade com o laptop UCA, seus softwares e ambientes digitais de forma geral, a exemplo da participação e utilização de redes socais, blogs, produção de materiais utilizando softwares de edição de áudio e imagens, bem como o desenvolvimento de projetos de integração dos laptops nas práticas pedagógicas. 
Semana passada mesmo, eu fui pegar uns livros [...] aí quando eu saí pra pegar... dois escondidos ali... [...] é... dois alunos escondidos. [...] quando eu voltei, eu fui buscar eles [...]. E chamei o pai, e veio a mãe. [...] eles saíram logo cedo pra escola e não voltaram. Ficam escolhendo o melhor lugar pra pegar o sinal. (C1 Escola C).

A escola passa a ter outro significado para os alunos e suas famílias, ela passa a ser um território de conectividade, de interatividade, de vivências de outras experiências e aprendizados. O aluno, de posse do laptop e da rede internet, desterritorializa a escola das rotinas, dos ritmos pré-determinados, lineares e a reterritorializa como um espaço seu, livre, de buscas, de aprendizados, de interatividade. Os alunos buscam cantinhos onde a conexão é melhor e não podem ser vistos para não serem mandados embora. Reterritorializam a escola como um local de conexão, de acesso, de vivência da cultura digital. Mesmo que a escola não possua ou não consiga desenvolver um projeto pedagógico forte, não fortaleça os professores para implementar o uso das tecnologias em suas práticas, o cotidiano da escola foi alterado com a presença da infraestrutura, principalmente de rede aberta, que possibilitou aos alunos construírem espaços/ tempos outros, de vivências e de interação com o contexto digital.

Os alunos não apenas buscam conectividade na escola, eles também a levam à escola, através de seus celulares, com seus planos de serviço. Com estes dispositivos, circulam pelos espaços dos corredores, do pátio e salas de aula, conectados, criando outros territórios. A dinâmica de circulação entre os tempos/ espaços mais rígidos e os mais fluidos faz parte do cotidiano desses interagentes/ praticantes que controlam e decidem a hora de sair de um e entrar no outro, como o aluno da escola B, que coloca o fone de ouvido para ausentar-se da escola que não lhe agrada, ou dos meninos da escola $C$, que também preferem ouvir música, para tentar sair da sala sem serem vistos. Seja através da conectividade ou de outros recursos, como as músicas que os alunos gravam, os mensageiros instantâneos ou o uso do Facebook, os alunos criam espaços que são só seus, e circulam entre territórios possíveis e imaginados, físicos e virtuais. O território possível, para esses alunos, é o imbricamento entre o território da escola e o território digital, uma mistura do que é dado e do que eles constroem no dia a dia, durante suas táticas evasivas da aula chata, das relações hierárquicas e da estética que lhes é oferecida. O território construído constitui-se desse estar dentro da escola, circulando por seus espaços, mas ligado a outros espaços/ tempos mais dinâmicos e fluidos. "Nisso, o papel do lugar é determinante. Ele não é apenas um quadro de vida, mas um espaço vivido, isto é, de experiência sempre renovada, o que permite, ao mesmo tempo, a reavaliação das heranças e a indagação sobre o presente e o futuro.” (SANTOS, 2013, p. 114). 
É assim que os alunos da escola A, aparentemente presos ao local, sem muitas possibilidades de deslocamento físico, em virtude das condições de infraestrutura da comunidade em que residem, e sem conectividade na escola, ao desenvolverem um projeto sobre o bairro, desterritorializam, mas o fazem diferentemente das demais escolas. Como a escola não oferece conectividade, a desterritorialização não se dá a partir dos espaços/tempos das redes, das comunidades virtuais, mas a partir do potencial das tecnologias digitais off-line. Ao gravar áudio e vídeo e manipular esses conteúdos, eles também vão recriando o espaço/tempo que habitam. Em primeiro lugar, eles reterritorializam a escola, pois todas as atividades também estão sendo realizadas em espaços/tempos outros que não apenas o da sala de aula e da escola. Estão num dentro-fora da escola, num dentro-fora da sala de aula, habitam as áreas livres, o prédio vizinho, trabalham em casa, vão ocupar o espaço da comunidade para fazer registros com seus laptops UCA. Em segundo lugar, através da manipulação dos conteúdos digitais, produzidos durante suas incursões pela comunidade, recriam seus territórios, recriam a escola e recriam o espaço do bairro. Eles são os protagonistas na construção de seus saberes, tirando a centralidade do processo da mão do professor e colocando todos, professores e alunos como colaboradores, que trabalham juntos para atingir um objetivo. Num projeto sobre sustentabilidade, onde produziram um vídeo de massinhas, a participação dos alunos extrapolou os diretamente envolvidos, o que acabou borrando as fronteiras entre os conteúdos, as séries e as idades. Ao produzir conteúdos digitalmente, os meninos trabalharam com a estética e puderam "dar uma nova cara" ao bairro, criando outras narrativas através de letras de músicas, de imagens, de programas de rádio e de vídeos.

\section{Considerações finais}

As tecnologias digitais móveis têm criado dinâmicas outras nos cotidianos escolares. O digital tem como característica a plasticidade, o movimento, a bricolagem e, agregado ao potencial das redes, favorece relações mais horizontalizadas, de produção, troca de saberes e de construção de conhecimentos. As crianças e jovens que vivenciam esses cotidianos têm sinalizado, a partir de suas táticas, do que encontram (laptops, celulares, redes $W i-F i$, planos pré-pagos), que é possível reterritorializar ambientes carentes de fruição e criar dinâmicas mais ricas de trocas, compartilhamento e construção coletiva de saberes, conhecimento e cultura. Estamos passando por transformações profundas cujo foco não está mais na memorização dos conteúdos, pois estes fluem pela rede, mas em como selecioná-los, 
tratá-los e remixá-los, demandando capacidade de análise, interpretação, síntese, crítica, na busca de uma perspectiva de criação e não de repetição.

A comunicação flui pela rede que os meninos e meninas estabelecem entre si. Eles e os aparelhos estão frente a frente, olho/tela, tela/olho, e a disponibilidade entre eles é instantânea, eles estão always on (PELLANDA, 2009), é só enviar uma mensagem que logo vem a resposta. Isso contrasta e coloca sob tensão a dinâmica da sala de aula, em que o professor está disponível por períodos restritos, quase não tendo tempo reservado para uma interação mais fluida com a turma, uma vez que precisa focar nos conteúdos, dar conta das rotinas escolares e cumprir com o estipulado na grade curricular.

O conjunto de práticas vivenciais que a mobilidade nos coloca, a dinamização e potencialização do pensamento, do deslocamento e da troca de informação, mediados pelas tecnologias digitais móveis, proporcionam um desprendimento das amarras de um contexto imediato, das limitações de um espaço/tempo cronológicos, delimitados, e sugerem aos interagentes/praticantes serem produtores de espaços/tempos mais fluidos e flexíveis. Esses espaços/tempos vão sendo construídos e reconstruídos à medida que esses nômades percorrem distâncias inimaginadas, sentados em suas carteiras, a exemplo dos nômades do deserto, que se deslocam sem sair do lugar. (DELEUZE; GUATTARI, 2012). Somos todos nômades, abandonando espaços/tempos fragmentados, destituídos de significado e lógica. Construímos coletivamente espaços de interação, vivência e experimentação mais significativos, que se renovam constantemente. O nômade desterritorializa, mas sempre há uma reterritorialização, a criação de novos territórios.

Esses são apenas alguns processos e práticas que estão sendo reconstruídos na contemporaneidade, diante das tecnologias digitais móveis, e que não coincidem mais com as maneiras de fazer educação, próprias do cotidiano escolar analógico. O ruído que tem causado a presença dos dispositivos digitais, o incômodo que alguns professores têm sentido, são apenas indícios de que algo vai mal, que tem alguma coisa que não se encaixa, que deve ser repensado e que vai bem além do tilintar dos aparelhos. Percebemos, nas falas dos professores e alunos, nas tensões que fazem parte dos cotidianos, os indícios de que os velhos modelos de escola e educação não se sustentam mais. Aquele modelo em que o professor recebe uma formação para passar conhecimento referenciado, que planeja igual para todas as turmas, para o ano todo, contemplando todo o conteúdo da grade, não funciona mais. E não funciona mais porque as dinâmicas, as práticas sociais do cotidiano mudaram vertiginosamente nas últimas décadas, o conhecimento selecionado e organizado previamente para fazer parte da grade comum das escolas, para fazer parte dos livros didáticos enviados pelo governo, todos são passíveis de serem questionados diante da multiplicidade de realidades onde se 
encontram nossos praticantes/interagentes. Serres (2013) chama atenção de que não é o aluno que chega sabendo tudo na escola, muito pelo contrário, esses alunos vêm com carências e defasagens muito grandes em relação aos conhecimentos formais e culturais, mas há necessidade de se estar atento às demandas desses alunos. Os professores e a escola vão começar a fazer sentido para esses alunos e alunas no momento em que forem ouvidos em suas necessidades, e se criem maneiras de atendê-las. Só assim a escola voltará a ter significado!

\section{REFERÊNCIAS}

ALVES, N. O espaço escolar e suas marcas: o espaço como dimensão material do currículo. Rio de Janeiro: DP\&A, 1998.

BACHELARD, G. A intuição do instante. Tradução de: Antonio de Padua Danesi. Campinas, SP: Verus, 2007.

CERTEAU, M. A invenção do cotidiano. 1. artes do fazer. Tradução de: Ephraim F. Alvez. 15. ed. Petrópolis, SP: Vozes, 2008.

CERTEAU, M.; GIRARD, L.; MAYOL, P. A invenção do cotidiano. 2. Morar e cozinhar. Tradução de: Ephraim F. Alvez e Lúcia Endlich Orth. 8. ed. Petrópolis, SP: Vozes, 2008.

DELEUZE, G.; GUATTARI, F. Mil Platôs: capitalismos e esquizofrenia. Tradução de: Peter Pál Pelbart e Janice Caiafa. 2. ed. Rio de Janeiro: Editora 34, 2012. v. 5.

GINZBURG, C. Mitos, emblemas, sinais. 2. ed. Tradução de: Federico Carotti. São Paulo: Companhia das Letras, 1989.

GREEN, B.; BIGUM, C. Alienígenas na sala de aula. In: SILVA, T. T. (Org.). Alienigenas na sala de aula: uma introdução aos estudos culturais em educação. 8. ed. Petrópolis, RJ: Vozes, 2009. p. 208-243.

HELLER, A. O cotidiano e a história. Tradução de: Carlos Nelson Coutinho e Leandro Konder. São Paulo: Paz e Terra, 2008.

LEFEBVRE, H. A vida cotidiana no mundo moderno. Tradução de: Alcides João Barros. São Paulo: Ática, 1991.

LEMOS, A. (Org.). Cidade Digital. Portais, inclusão e redes no Brasil. Salvador: Edufba, 2007.

LEMOS, A. Cibercultura. Tecnologia e Vida Social na Cultura Contemporânea. Porto Alegre: Sulina, 2008a.

LEMOS, A. Ciberespaço e tecnologias móveis: processos de territorialização e des territorialização na cibercultura. In: MÉDOLA, A. S.; ARAÚJO, A.; BRUNO, F. (Org.). Imagem, visibilidade e cultura midiática. Porto Alegre: Sulina, 2008b. p. 277-293. 
LEMOS, A. Cultura da mobilidade. Revista FAMECOS, Porto Alegre, n. 40, p. 28-35, dez. 2009a.

LEMOS, A. Cibercultura como território recombinante. In: TRIVINHO, E.; CAZELOTO, E. (Orgs.). A cibercultura e seu espelho [recurso eletrônico]: campo de conhecimento emergente na nova vivência humana na era da imersão interativa. São Paulo: Instituto Itaú Cultural, 2009b. p. 38-46. Disponível em: < http://abciber.org/publicacoes/livro1/a cibercultura_e_seu_espelho.pdf $>$. Acesso em: 25 maio 2012.

LEMOS, A.; LÉVY, P. O Futuro da Internet. Em direção a uma ciberdemocracia planetária. São Paulo: Paulus, 2010.

LÉVY, P. A inteligência coletiva: por uma antropologia do ciberespaço. São Paulo: Loyola, 1998.

LÉVY, P. Cibercultura. São Paulo: Ed. 34, 1999.

MARTIN-BARBERO, J. Oficio de cartógrafo: travessias latino-americanas da comunicação na cultura. São Paulo: Loyola, 2004.

PELLANDA, E. C. Nomadismo em espaços sociais: uma discussão sobre as novas formas de inteirações potencializadas pela mobilidade da informação. In: CONGRESSO BRASILEIRO DE CIÊNCIAS DA COMUNICAÇÃO, 29., 2006, Brasília. Anais... São Paulo: Intercom, 2006. CD-ROM.

PELLANDA, E. C. Comunicação móvel: das potencialidades aos usos e aplicações. Em Questão, Porto Alegre, v. 15, n. 1, p. 89-98, 2009.

PRIMO, A. Interação mediada por computador: comunicação, cibercultura, cognição. 2. ed. Porto Alegre: Sulina, 2008.

SANTAELLA, L. Linguagens líquidas na era da mobilidade. São Paulo: Paulus, 2007.

SANTOS, M. Por uma outra globalização: do pensamento único à consciência universal. Rio de Janeiro e São Paulo: Record, 2013.

SERRES, M. Polegarzinha. Tradução de: Jorge Bastos. Rio de Janeiro: Bertrand Brasil, 2013.

SOUZA E SILVA, A. Arte e tecnologias móveis: hibridizando espaços públicos. In: PARENTE, A. (Org.). Tramas na rede: novas dimensões filosóficas, estéticas e políticas da comunicação. Porto Alegre: Sulina, 2004. p. 282-297.

TAPSCOTT, D. A hora da geração digital. Como os jovens que cresceram usando a internet estão mudando tudo, das empresas aos governos. Rio de Janeiro: Agir Negócios, 2010.

Texto recebido em 17 de março de 2015.

Texto aprovado em 18 de junho de 2015. 
